\title{
Succession Planning and Leadership Development in a Faculty of Health Sciences
}

\author{
Bethuel Sibongiseni Ngcamu ${ }^{1}$ \\ ${ }^{1}$ Management and Governance department, Walter Sisulu University (Buffalo City Campus), South Africa \\ Correspondence: Bethuel Sibongiseni Ngcamu, Management and Governance department, Walter Sisulu \\ University (Buffalo City Campus), South Africa. Tel: 43-708-5222. E-mail: ngcamuzaa@gmail.com
}

Received: April 28, 2019 Accepted: July 22, 2019 Online Published: September 16, 2019

doi:10.5539/gjhs.v11n11p101 URL: https://doi.org/10.5539/gjhs.v11n11p101

\begin{abstract}
Background: The challenges in the Faculty of Health Sciences in universities are unique and complex. These dynamic faculties require decisive and strong leadership, smooth systems and business processes, succession plans and development opportunities. These challenges in these faculties are exacerbated by the fact that the roles and responsibilities of the Heads of Departments are multifaceted. Those who are heading them are not acclimatising to the responsibilities because of the lack of support to develop and succeed in their positions. This study therefor seeks to determine challenges faced by the HoDs in the Faculty of Health Sciences, and the succession plans, competences and development programmes that are in place to develop future leadership talent in a university in South Africa.
\end{abstract}

Methods: A single case study approach was employed whereby qualitative in-depth interviews were conducted with nine HoDs and a faculty dean as well as the observation and document analysis. The grounded theory as an inductive process was used to categorise and code data where themes and trends emerged from the data.

Results: Four major themes emerged from the data:

- The university, faculty and departments within the faculty did not have succession plans while the strategic positions were occupied by post-retirees.

- The Faculty did not have competent employees who could ascend to academic leadership positions in the faculty.

- There was limited growth in the Faculty due to the absence of the developmental programmes.

- There was a plethora of challenges including the shortage of office equipment, absence of the mentoring programmes, structural fragmentation and inefficiencies in the Human Resource Department (HRD).

Conclusions: A pervasive crisis was observed in this particular Faculty of Health Sciences during the turbulent times in universities. It is crucial for the HoDs to receive quality support from the administrative departments such as HRD in order for them to achieve the departmental objectives. The HoDs' leadership capabilities and effectiveness can be enhanced by mainstreaming the human resources business systems, development, mentoring and coaching, as well as the implementation of well-coordinated succession plans.

Keyswords: grounded theory, leadership development, mentoring, successions planning

\section{Background}

The health faculties in South Africa are led by ageing leadership with succession plans and leadership programmes absent, generic, anecdotal and not ingrained into the medical undergraduate curriculum. Models to audit health faculties' leadership in knowledge, competencies and skills are not in place. The crisis seen in these faculties is exacerbated by the universities' failure to attract and retain young qualified and competent leaders. Whilst leadership and leadership development has been pinpointed as a significant aspect for success in the health academic fraternity. This study sought to determine challenges faced by the Faculty of Health Sciences' heads of departments at a particular university in South Africa in order to achieve their departmental objectives. This study further explored a plan for successors in the long term or during emergencies, as well as the availability of staff members with a broader span of competencies and qualities within the faculty. This study also investigates processes or development programmes in place to create a pipeline of future leadership talent. The South African Medical Faculties are experiencing a leadership crisis due to the absence of the succession plans, span of 
competencies, strategies in place to develop leaders and complex challenges which discouraging succession plans. The current research study aims to achieve the following objectives:

- To investigate succession plans effectiveness and its impacts within a faculty.

- To determine the faculty leadership's competencies in achieving the faculty objectives.

- To explore strategies in place to develop employees on leadership development.

- To determine an existing challenges discouraging succession plans in the faculty.

A number of commentators (Fitzpatrick, 2014; Lieff et al., 2013; Turner, 2018; Sherk et al., 2009) suggest that HoDs who are employed by the health industry should possess competencies and skills to find solutions to the human resource crisis as their roles are multifaceted as it is difficult to attract quality employees into leadership positions. Turner (2018) cites various competencies which should be possessed by leaders in these faculties, which include knowledge on dynamics in organisations, personal capabilities and professionalism. The author further argues that succession planning should take into account previous competencies when recruiting and selecting employees to lead and manage health institutions. Harper, Leider, Coronado, and Beck (2018) suggest that by 2020 more than $25 \%$ in the health sector will retire whilst succession planning activities are not being addressed in health institutions. In the US, between 9 and 16 percent of all medical school deans in 2017 were employed in an acting capacity (Bunton, Sass, Sloane, \& Grigsby, 2018).

Conversely, universities are failing to develop succession plans (Haragreaves, 2015) and the medical degree's curriculum does not even include such plans (Spendlove, 2015). Grigsby et al. (2009) posit that during transition periods in leadership, succession planning, leadership development and mentoring programmes and initial steps to meet the needs of academic departments are essential. Debowski (2015) opines that the development and support of good leadership in universities are missing despite a dire need for talented leaders during these turbulent times in the sector, which are characterised by poor performance with respect to viable and well-considered strategy.

Spendlove's (2007) research study on exploring leadership competencies at senior managerial levels at British universities suggested that succession planning and strategies should be incorporated into leadership development programmes. An investigation performed by McMurray, Henly, Chaboyer, Clapton, Lizzio \& Teml (2012) on the Health Faculty at an Australian University on succession planning using Kirkpatrik's (1959) model on evaluating employees' perceptions on the leadership programme ended up being enthusiastic in occupying leadership positions.

William, Kavin and Linda (2016: 465) suggest that though industries and health related departments have planned leadership pathways, medical health HoDs have received minimal attention and focus. These authors highlights in their commentary a need for transparency on the succession planning processes. William et al (2016: 465) mention a plethora of approaches to enable a succession plan a success which includes both a HoD and Faculty Dean to be cautious thoughtful and open discussions. The aforesaid global crisis on the succession planning has been noted by Knapp, Wright, Clarke, McAnulla \& Nightingale (2017) on their study conducted to 24 universities in the United Kingdom (UK). The research study explored the age and retirement profile of the age and retirement profile of the academic radiography employees. The study found a total of $30 \%$ of radiographers who were due to retire within 10 years with over $25 \%$ holding doctorates qualification included in this figure and those entering the field having lesser qualifications. Meanwhile, Grimm, Brandert, Palm \& Svobo (2016) indicate that the department of Health in Nebraska \& the University of Nebraska Medical Centre developed a comprehensive approach to assess the education and training needs of employees and developed a workforce development plans to address those needs. The EDIC method was followed which included Engaging stakeholders, Developing assessments, Identifying training needs and Create development plans. The method used was grounded in science and practice which allowed inputs from different stakeholders and produced buy-in from staff members at all employment categories. In order to determine workforce's training needs and designing a training programme, Bharwani, Kline \& Patterson (2017) utilised a stakeholders-based and a bottom-up approach in contrast to a top-down approach in a Canadian University Medical School. A qualitative semi-structured interviews (77 actors) was conducted with five themes emerging which includes formal programming, organisational support, programme evaluation, skill development and participant selection. The authors concluded that development programmes should focus on developing self-awareness, communication skills and team-building capability amongst employees and that programmes should be constantly.

Universities in South Africa are facing unique challenges and constraints as they are dealing with mostly with merged and more complex institutions with senior leaders unable to respond to these current developments with relevant, responsive and appropriate leadership development programmes. According to Dopson, Ferlie, 
McGivern, Fischer, Mitra \& Ledger (2018:1), university settings are changing radically throughout the world, and leadership roles and responsibilities are complex and require diverse approaches. They posit that there is a paucity of literature on leadership development to support complex leadership roles in universities, and South Africa is no exception. Dopson et al. (2018:4) argue that although the higher education industry is a knowledge-based sector, it has failed to study its effectiveness meticulously. Dopson et al. (2018:5) opine that there are limited leadership development interventions in the university sector that have a reliable evidence base and are theoretically well-informed.

Grunberg, Barry, Kleber, McManigle and Schoomaker (2018) indicate that a plethora of medical schools have initiated leader and Leadership Education and Development (LED) programmes to develop physical leaders. Bryman \& Lilley (2009) focussed on the characteristics in universities that generate leadership content, which includes collegiality amongst the academic staff members, discipline, loyalty, individuality and autonomy and employee's resistance to management while Debowski (2015) suggested that consultation and respect for employees which can form the content for leadership development in universities. Meanwhile, Grunberg et al. (2018) concluded in their perception study on public and private US medical school and university participants engaged in the LED programmes that there is no consensus on whether teaching leadership is crucial, who teach, what content (topics) to teach and where leadership fits into the curriculum during medical school. The participants in the same study consistently agreed that the LED programmes should be provided to undergraduate medical education. Meanwhile, Bikmoradi, Brommel, Shoghli, Khorasani-Zavareh and Masiello (2010) explored the leadership challenges perceived by academic managers (18 participants) in medical schools in Iran found challenges which evolved around inefficacy of academic governance, styles of management, congruence between authority and responsibilities, low motivation and a boss-centred environment.

An experimental study performed by Lieff, Banack, Baker, Martimianakis, Verma, Whitesid \& Reeves (2013) on a Canadian University, Faculty of Medicine to ascertain the needs of department chairs and development opportunities espoused that they were not prepared to perform their activities effectively. The latter finding was supported by a plethora of researchers on the essential competencies, which are needed in health science faculties in universities including structural awareness; network support; strategy planning and interpersonal skills (Grigsby et al. 2009; Lieff et al. 2013). While Lieff et al. (2013) added competencies, which can realise organisational goals, improve performance and efficiency as including cultural awareness, knowledge sharing, emotional support and influence skills. Whereas, Grigsby et al. (2009) included communication and conflict resolution skills and solving adaptive challenges, Dubinsky et al. (2015) added budgeting and mentoring. In addition to the challenges observed in medical schools, Mullan et al. (2011) conducted a study in a Sub-Saharan African Medical School and found weak physical infrastructure, unreliable water, poor telecommunications, daily power outages, an insufficient number of computers and restrictions in internet connectivity.

The critically reviewed literature above depicts that little research has been conducted on the succession plans at universities, competencies possessed by leaders, the absence of the leadership development programmes and their challenges thereof. The existing literature is anecdotal with limited qualitative in-depth interview studies being condicted, which necessitates this study to fill a void.

\section{Method}

This research study followed a qualitative research approach where a researcher attempted to understand succession plans and leadership development programmes in a university faculty holistically (Merrian \& Tisdell, 2015: 242). To assist the researcher to understand the challenges of succession planning, development plans and competencies faced by the HoDs, a researcher adopted an exploratory single case study (Saunders et al. 2007), which is the Faculty of Health Sciences. This qualitative study gave answers to the set questions on the effectiveness of the succession plans, span of competencies possessed by the faculty leaders, strategies to develop them and challenges that paralysis succession plans in this faculty (Basias \& Pollalis, 2018). The questions which this researcher attempted to answer are as follows:

- What are the challenges facing the faculty/department which enable you or your subordinates to achieve the departmental faculty/university objectives?

- Do you have employees with a broader span of competencies occupying leadership positions in your department?

- What development programmes are in place to create leadership talent? 


\subsection{Setting}

The researcher studied the Faculty HoDs and a Dean at a university located in a rural province in South Africa. The faculty had a total of 351 academic and academic support staff members with 38 employees at postretirement (65 and above), 21 between 60 and 65 years of age, 25 between 50 and 60 years of age. There were 230 vacant positions in the faculty. The faculty is located in different sites including the medical campus, public hospitals and research centres. The Faculty of Health Sciences administration is in the university though there is a bilateral agreement with the Provincial Department of Health. Fifty-three Joint Staff Establishment Staff (JES) members were employed by both the university and the Provincial Department of Health. The HoDs were not employed permanently in their positions instead, they received an allowance. The HoDs activities included learning and teaching, research, community engagement, and quality assurance for the programme.

\subsection{Data Collection}

A qualitative in-depth interviews (King, 2004) were conducted to nine out of eleven departmental heads and one dean who consented to participate in this study. The researcher conducted 60-minute long unstructured interviews, observations and document analysis (Saunders et al. 2007) from January to December 2018. The researcher's background in organisational development allowed him to probe and explore more deeply than a research assistant could. The interviews, which were considered anonymous, were recorded using a voice recorder and transcribed.

\subsection{Data Analysis}

The study followed grounded theory as an analytical approach to qualitative data. Grounded theory commonly used in healthcare qualitative inquiries due to its pragmatic orientation on the problems faced by the research participants. The data generated theoretical insights as themes for this study (Chapman, Hadfield, \& Chapman, 2015). The collection of information from the research subjects was categorised and compared continuously until latent patterns, themes and trends emerged. In order to avoid covering subjective professional views, the interview transcripts were reread, cross-referenced and notes were made inductively making. The set of information was therefore, codified to depict the meaning of the phrase to index the collection of information and phrases with similar meaning were grouped. To minimise bias in this study as it has a high degree of subjectivity, codes were used for further analysis and demonstration of validity. A network of association was generated by combining and contrasting codes to develop themes. The themes that emerged from the data analysis were sense-checked against new data and influenced ongoing data collection.

\subsection{Ethical Guidelines}

The individual employees consented to participating in this study and anonymity and confidentiality were maintained. Research rigour was established according to the dimensions of "trustworthiness" for qualitative research findings such as transferability, dependability, confirmability, and credibility. Transferability of the data was achieved primarily through a rich description of the phenomenon under investigation. The team approach to data analysis enhanced the dependability of findings. Confirmability was improved through an audit trail, which provided a transparent description of the research process from start to finish. Finally, investigator triangulation assisted in establishing credibility.

\section{Results}

The categories that emerged in this study were grouped into four main categories: succession plan, span of competencies, strategies to develop employees, and management process to create future leadership talent and challenges discouraging the succession plan.

\subsection{Succession Plan for the Faculty}

It was established that the majority of the interviewees indicated that there was no succession plan in the faculty and their respective departments. Very few interviewees indicated that they had delegated some of the activities to their young subordinates because the majority of their staff members were above 65 years of age. Furthermore, some indicated that foreigners dominate the faculty. Although there was a postgraduate programme that produced scientists, there was no system in the university to incorporate local scientists. The interviewees suggested that the university must send employees to leadership development programmes.

\subsection{Span of Competencies in the Faculty Leadership}

The respondents opined that their departments lacked senior members with various competencies who could occupy a senior position including that of the HoD. The subjects have consistently agreed that it is challenging to grow in the university due to the lack of external training organised by the university. Another hindrance to this challenge is the fact that there were employees who have been in the employ of the university for four years in a 
contract position. While professional growth in this university is stagnant, there are staff members who are striving for progress by mentoring young consultants on problem-based learning. The participants postulated that there were younger employees who required appropriate training on the human resource processes, practices, and policies, as well as on emotional intelligence. The only dilemma raised was that the most capable ones were employed on contract. They exemplified the fact that a private college recruited the competent employees in the department. Private colleges are believed to offer more lucrative financial compensation than the universities. They posited that while some departments have lecture halls, they were ill-equipped and in a state of disrepair.

\subsection{Strategies to Develop Employees in the University}

The majority of the informants in the faculty alluded to the fact that three academics were in the process of enrolling for the leadership courses. These employees were performing leadership activities in their respective departments including coordinating academic programmes, managing research, learning and teaching, as well as community engagement. These employees were also serving in various committees including the ethics committee. A number of informants disputed the above scenario by indicating that:

“...there is no leadership development plan throughout the university. This can be attested by the fact that there are no off-the job trainings organised by the university."

The HoDs opined that in their departments, they train academics to be specialists and five members of staff, funded by the National Research Fund (NRF), were currently enrolled for PHDs at the University of Stellenbosch. Another actor who occupies a leadership position in this faculty painted a bleak picture that contradicts the above sentiments:

"The department is accredited for postgraduate studies, and specialists we have in the department are above the age 65 years. The university offers a Post-Retirement contract for one year, which is a disadvantage for specialists to conduct research and develop other staff members and students in order to be specialist. Henceforth, to headhunt or recruit specialist in this geographical area or within this discipline is a nightmare".

A dominant highlight for the HoDs was on the broken culture and fragmented systems. They have proclaimed that the university does not want change; bureaucratic culture towards research, learning and teaching and community engagement was reactionary. They have asserted that matters were exacerbated by the incompetence levels of the HR department's staff members, which disabled the academic enterprise. They have further suggested that all employees should be trained in leadership skills.

\subsection{Challenges Discouraging the Succession Plans}

The HoDs in this department were acutely aware of the challenges faced, which are categorised as equipment shortages, human resources management department inefficiencies and leadership development and structural fragmentation (see Table 1). Furthermore, their roles and responsibilities as HoDs were unclear or not known.

Table 1. Challenges faced by HoDs

\begin{tabular}{|c|c|}
\hline Equipment/tools of the trade & Absence of mentorship and coaching programmes \\
\hline $\begin{array}{l}\text { - There was no equipment such as telephones and } \\
\text { printers. } \\
\text { - } \quad \text { Furniture was lacking or broken in the lecture halls. } \\
\text { - } \quad \text { Teaching space was insufficient } \\
\text { - } \quad \text { Laboratory space was insufficient } \\
\text { - } \quad \text { No research labs } \\
\text { - } \quad \text { Equipment in laboratories was very old }\end{array}$ & $\begin{array}{l}\text { - There were no mentorship and coaching programmes at the } \\
\text { university. }\end{array}$ \\
\hline $\begin{array}{l}\text { Structural fragmentation } \\
\text { - The reporting lines were unclear. } \\
\text { - There was a shortage of staff. } \\
\text { - Some members of staff in the faculty were in } \\
\text { post-retirement. } \\
\text { - There was a problem to attract new staff members. }\end{array}$ & $\begin{array}{l}\text { Human resources department inefficiencies } \\
\text { - There was an induction programme. } \\
\text { - There were no job descriptions. } \\
\text { - There was no probation. } \\
\text { - Organogram was circulated to staff for comments. Staff } \\
\text { responded that it was not feasible to implement the }\end{array}$ \\
\hline
\end{tabular}


- The HR processes were not customer- friendly as recruitment and selection takes years.

- Salaries were lower than in other departments within the faculty. There is no performance management system.

- There was no planning on employee performance.

- HoDs found it difficult to manage performance.

- There were no systems in place to deal with poor performers, and it became a hindrance.

Source: author.

\subsection{Observation (Researcher)}

The above findings were supported by the researcher's observation during the period of investigation, and the findings are as follows:

- There was no management of Human Resources (HR) staff members which paralyses the academic enterprise.

- The HR recruitment and selection processes were broken, ineffective and inefficient which affects the academic Faculty of Health Sciences.

- The HR department's management denied allegations of ineffectiveness and inefficiencies.

- There was poor support of the HR department to the academic line managers.

- The claims of poor interpersonal relationship within the faculty were evidenced by the destructive conflict with unethical emails by a junior staff member to the Faculty Dean.

- The challenges advanced by HoDs was that someone could infer that the Faculty had no leadership prior to the current Dean or that it was poorly managed.

- Basic tools of the trade such as telephones and laptops for the leadership were not available. The secretaries were using their cell phones because the landline phones malfunctioned.

- There were similar challenges on the shortage of staff members in all the departments as opposed to the unfilled budgeted and active positions. These positions were occupied by the post-retirees without initiating the processes of advertising and filling them.

- The HR business model was input-oriented with a focus on the recruitment and selection processes.

\section{Discussion of Data}

\subsection{Succession Plan for the Faculty}

The data revealed that there was no succession plan in the faculty although members who were above 65 years and foreign nationals dominated the senior posts, which further illuminated that development programmes opposed local scientists' upward mobility. A plethora of researchers (Grigsby et al., 2009; Spendlove, 2007) opine that succession planning plays a pivotal role in preparing the needs of academic departments and should be incorporated into leadership development programmes. The published literature on the succession planning in the health sciences at universities is lacking, and it does not address the issue that ageing foreign nationals are occupying strategic positions as espoused by the current study findings.

\subsection{Span of Competencies in the Faculty Leadership}

HoDs discussed the unavailability of senior members who possess competencies and traits required by the faculty in their departments. They further articulated that this was exacerbated by the absence of the off-the-job trainings, which were planned by the university. Numerous researchers (Grigsby, 2009; Turner, 2018) believe that Health Sciences department leaders should have competencies that include personal insight, professional credibility and understanding of an organisation's dynamics. While Dubinsky et al. (2015) differed by mentioning strategic planning, budgeting, mentoring and network development are necessary to achieve organisational goals.

\subsection{Strategies to Develop Employees in the University}

The internal succession plans made by the HoDs by delegating management and leadership activities to their subordinates were noteworthy. Whilst this has been disputed by numerous HoDs that throughout the university 
there were no leadership development plans. According to Dopson et al. (2018), there is a paucity of literature on leadership development to support complex roles in universities, as well as limited leadership interventions. This has been aggravated by contested debates on the leadership development syllabus, and content in the medical industry. Bryman and Lilley (2009) mentioned that it should include personal, interpersonal and intellectual capability with Debowski (2015) suggesting the core values and principles should be included in the syllabus. Meanwhile, Grunberg et al. (2018) concluded that leadership development should be integrated into the undergraduate medical curriculum.

\section{Conclusion}

The study observed that the HoDs were insufficiently prepared and incompetent in their current roles and responsibilities. The current conundrum clearly depicts the risks faced by the faculty, the university and students as clients as experienced scientists are at the post-retirement with no succession plans in place. Furthermore, the leadership crisis in this faculty is associated with the human resources department's inefficiencies and input-orientated business operating model, which is not responsive to client needs. Conversely, the current crisis in this faculty requires strong administrative support, leadership development, market competitive remuneration, succession plans and retention strategies for young and emerging scientists to remedy the current situation. There are methodological limitations in this study as the qualitative in-depth interviews were conducted to the HoDs and a Faculty Dean without including their subordinates. Future researchers should extend this study to other medical schools by testing the perceptions of all key stakeholders in the succession planning and leadership development strategies.

\section{Competing Interests Statement}

The authors declare that there are no competing or potential conflicts of interest.

\section{References}

Basias, N., \& Pollalis, Y. (2018). Quantitative and qualitative research in business \& technology: Justifying a suitable research methodology. Review of Integrative Business and Economics Research, 7, 91-105.

Bharwani, A., Kline, T., \& Patterson, M. (2017). A stakeholder-based approach to leadership development training: the case of medical education in Canada. International Journal of Training and Development, 21(3), 211-223. https://doi.org/10.1111/ijtd.12104

Bikmoradi, A., Brommels, M., Shoghli, A., Khorasani-Zavareh, D., \& Masiello, I. (2010). Identifying challenges for academic leadership in medical universities in Iran. Medical Education, 44(5), 459-67. https://doi.org/10.1111/j.1365-2923.2009.03570.x

Bryman, A., \& Lilley, S. (2009). Leadership researchers on leadership in higher education. Leadership, 5(3), 331-46. https://doi.org/10.1177/1742715009337764

Bunton, S. A., Sass, P., \& Sloane, R. A. (2018). Grigsby R K. Characteristics of Interim Deans at US Medical Schools: Implications for Institutions and Individuals. Academic Medicine, 93(2), 241-5. https://doi.org/10.1097/ACM.0000000000001920

Chapman, A. L, Hadfield, M., \& Chapman, C. J. (2015). Qualitative research in healthcare: an introduction to grounded theory using thematic analysis. Journal of the Royal College of Physicians of Edinburgh, 45(3), 201-5. https://doi.org/10.4997/JRCPE.2015.305

Dopson, S., Ferlie, E., McGivern., G, Fischer., M. D., Mitra, M., Ledger, J., \& Behrens, S. (2018). Leadership development in Higher Education: A literature review and implications for programme redesign. Higher Education Quarterly. https://doi.org/10.1111/hequ.12194

Fitzpatric, S. (2014). A Survey of Staffing Levels of Medical Clinical Academics in UK Medical Schools as at 31 July 2013. A report by the Medical Schools Council 2014 (1-38). https://doi.org/10.1097/ACM.0b013e3181b6b1bb

Grimm, B. L., Brandert, K., Palm, D., \& Svoboda, C. (2017). The EDIC method: An engaging and comprehensive approach for creating health department workforce development plans. Health promotion practice, 18(5), 688-695. https://doi.org/10.1177/1524839916671301

Grunberg, N. E., Barry, E. S., Callahan, C. W, Kleber, H. G., McManigle, J. E., \& Schoomaker, E. B. (2018). A conceptual framework for leader and leadership education and development. International Journal of Leadership in Education, 6(1-7), 1-16. https://doi.org/10.1080/13603124.2018.1492026

Hargreaves, A. (2005). Leadership succession. In The educational forum, 30(2), 163-173. 
https://doi.org/10.1080/00131720508984680

Harper, E., Leider, J. P., Coronado, F., \& Beck, A. J. (2018). Succession planning in state health agencies in the United States: a brief report. Journal of Public Health Management and Practice, 24(5), 473-8. https://doi.org/10.1097/PHH.0000000000000700

King, N. (2004). Using interviews in qualitative research. Essential guide to qualitative methods in organizational research, 2, 11-22. https://doi.org/10.4135/9781446280119.n2

Knapp, K. M., Wright, C., Clarke, H., McAnulla, S. J., \& Nightingale, J. M. (2017). The academic radiography workforce: age profile, succession planning and academic development. Radiography, 23, S48-S52. https://doi.org/10.1016/j.radi.2017.05.012

Lieff, S., Banack, J. G., Baker, L., Martimianakis, M. A., Verma, S., Whiteside, C., \& Reeves, S. (2013). Understanding the needs of department chairs in academic medicine. Academic Medicine, 88(7), 960-6. https://doi.org/10.1097/ACM.0b013e318294ff36

McMurray, A. M., Henly, D., Chaboyer, W., Clapton, J., Lizzio, A., \& Teml, M. (2012). Leadership succession management in a university health faculty. Journal of Higher Education Policy and Management, 34(4), 365-76. https://doi.org/10.1080/1360080X.2012.689198

Merriam, S. B., \& Tisdell, E. J. (2015). Qualitative research: A guide to design and implementation. John Wiley \& Sons.

Mullan, F., Frehywot, S., Omaswa, F., Buch, E., Chen, C., Greysen, S. R., .. \& Diomande M J. (2011). Medical schools in sub-Saharan Africa. The Lancet, 377(9771), 1113-21. https://doi.org/10.1016/S0140-6736(10)61961-7

Rayburn, W., Grigsby, K., \& Brubaker, L. (2016). The strategic value of succession planning for department chairs. Academic Medicine, 91(4), 465-468. https://doi.org/10.1097/ACM.0000000000000990

Saha, S., \& Wish, J. B. (2018). Leading the Dialysis Unit: Role of the Medical Director. Advances in chronic kidney disease, 25(6), 499-504. https://doi.org/10.1053/j.ackd.2018.03.004

Sherk, K. E., Nauseda, F., Johnson, S., \& Liston, D. (2009). An experience of virtual leadership development for human resource managers, Human resources for health, 7(1), 1-18. https://doi.org/10.1186/1478-4491-7-1

Spendlove, M. (2007). Competencies for effective leadership in higher education. International Journal of Educational Management, 21(5), 407-17. https://doi.org/10.1108/09513540710760183

Turner, P. (2018). Succession Planning and Leadership Development. In Talent Management in Healthcare (pp. 157-187). Palgrave Macmillan, Cham. https://doi.org/10.1007/978-3-319-57888-0_7

\section{Copyrights}

Copyright for this article is retained by the author(s), with first publication rights granted to the journal.

This is an open-access article distributed under the terms and conditions of the Creative Commons Attribution license (http://creativecommons.org/licenses/by/4.0/). 